\title{
MOHICANS: Mobile Learning Teaching Model for Next Gen Learners
}

\author{
Zhen Zhen Leow, Jason Chui, Cally Ng
}

School of Information Technology, Nanyang Polytechnic, Singapore.

\begin{abstract}
The proliferation of mobile devices among especially the younger (aka Next Gen) learners has led to a change in expectations when it comes to learning. These learners prefer to learn "on-the-go" and to have the learning contents at their fingertips. However, design strategies for mobile learning are still in nascent development stages. This research builds on existing literature in the field of mobile learning pedagogy to propose a novel teaching model for mobile learning which instructors can use to design their own courses.

The research is conducted on 120 identified learners from 2 faculties, School of IT and School of Health Sciences who were undertaking their respective core modules. The participating instructors designed and implemented mobile learning packages in accordance with the proposed teaching model. The authors collected feedback from learners via survey questionnaires on a fourpoint Likert scale to measure the level of learners' satisfaction with the mobile learning packages. The authors also examined the module learning outcomes to gauge the level of instructors' satisfaction as well as the competency levels achieved by the learners. Both qualitative data and sentiments collected from survey and classroom observations have been encouraging, showing that the teaching model proposed is effective.
\end{abstract}

Keywords: Mobile Learning; Teaching Model; Elearning; Mlearning; Quality Dimensions; Design Strategies. 


\section{Introduction}

Mobile electronic devices have come a long way, from being a niche technology to being an almost ubiquitous tool. In the realm of education, schools and educators are incorporating mobile learning into their curriculum steadily to tap on the affordances and availability of mobile devices.

In the past two decades, research into mobile learning has picked up pace, with numerous frameworks for mobile learning being suggested by different groups of researchers. At the same time, multiple reports have shown that there is a gap between the translation and adoption of research results and theories into actual practice in various fields.

This paper attempts to bridge this gap by presenting a novel teaching model that can be introduced between a theoretical framework and the concrete steps that educators can adopt to implement the rich body of research on mobile learning to their own curriculum design.

\section{Background}

The number of mobile phone users have steadily climbed throughout the years and is expected to exceed 5 billion in 2019 (Meena \& Kumar, 2017). Young people has adopted mobile technology so readily that the mobile phone has already become an essential component in their lives (Campbell, 2005), so much so that Ling (2000) even stated that the mobile phone is "at cross purpose with the mission of the school". Forward-looking researchers and institutions have accepted the paradigm shift, and many have embarked on incorporating mobile learning into their curriculum (Kljunić \& Vukovac, 2015; Oberer \& Erkollar, 2013; Taleb \& Sohrabi, 2012; Wang, Shen, Novak \& Pan, 2009).

It is Sharples et al. (2009), who have one of the more encompassing definitions of mobile learning. They unpacked mobile learning into 1) mobility in physical space, 2) mobility of technology, 3) mobility in conceptual space, 4) mobility in social space, and lastly 5) learning dispersed over time. Regardless of the definition, it is commonly recognized that mobile learning is a subset of electronic learning (elearning) with its own characteristics and constraints (Parsons \& Ryu, 2006).

In the past two decades, research into mobile learning has picked up pace, with numerous frameworks for mobile learning being suggested by different groups of researchers. Koole's (2009) FRAME (Framework for the Rational Analysis of Mobile Education) model "describes mobile learning as a process resulting from the convergence of mobile technologies, human learning capacities, and social interaction.” 


\section{Proposed Quality Dimensions}

Using Koole's FRAME model as the framework for choice, we propose two middle layers between the framework and actual practice to facilitate implementation. The layers split rationally into two layers, which also reduces the amount of information included at each layer. In the first layer, we crafted quality dimensions as rhetorical guiding questions that could be mapped from the overlaps between the circles in the FRAME model. As shown in Figure 1, we are using Koole's terminology where the three intersections are abbreviated by the terms DL (Device-Learner intersection), LS (Learner-Social intersection), and DS (Device-Social intersection). These questions were based on multiple research on mobile learning and aim to condense the knowledge and wisdom of these research yet not be too shallow and inflexible.

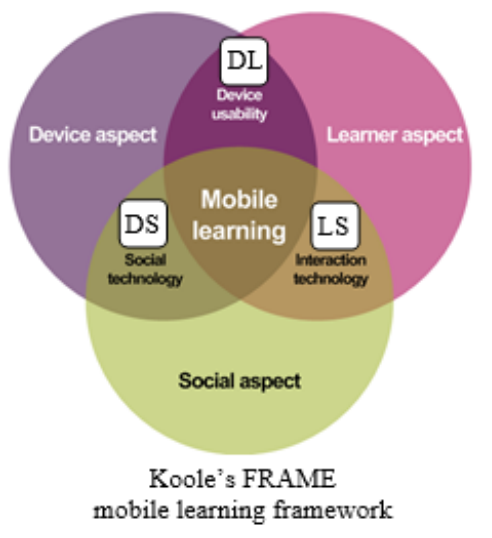

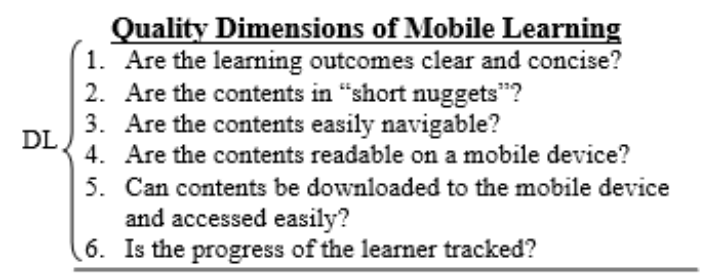
$\operatorname{LS}\{7$. Are there social interactions for learning between learners and between learners and instructor?

DS $\left\{\begin{array}{l}\text { 8. Are there formative/self-check and summative } \\ \text { assessments? } \\ \text { 9. Are there timely and constructive feedback to } \\ \text { support learners' learning? }\end{array}\right.$

Figure 1. Mapping of Koole's FRAME to Quality Dimensions

These nine questions will provide instructors with rhetorical questions to anchor their design in the theoretical framework. However, taking human behavioural science into consideration, we went one step further to create a mnemonic that gives instructors a "chunked" checklist to use when designing mobile lessons. We term the breakdown of this mnemonic "MOHICANS".

\section{Proposed Design Strategies}

The design strategies, "MOHICANS", proposed (see Figure 2) are extracted from both Koole's FRAME model as well as the quality dimensions discussed above. The first three design strategies are general design considerations that stem from the FRAME model directly, while the next five strategies are drawn directly from the quality dimensions. 
Quality Dimensions of Mobile Learning

1. Are the learning outcomes clear and concise? .......... C

2. Are the contents in "short nuggets"? ........................ C

3. Are the contents navigable? ……............................. I

4. Are the contents readable on a mobile device? ……... I

5. Can contents be downloaded to the mobile device and accessed easily?

6. Is the progress of the learner tracked?

7. Are there social interaction for learning between learners and between learners and instructor? ……... N

8. Are there formative/self-check assessments? …….... S

9. Are there timely and constructive feedback to support learners' learning?

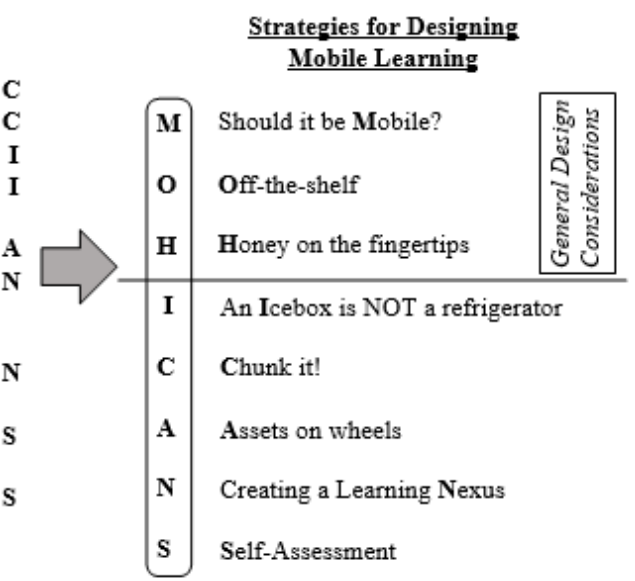

Figure 2. Mapping of Quality Dimensions to Design Strategies

\section{1. $M$ is for "Should it be Mobile"}

The first general design strategy for instructors will be to consider the most pertinent question: Is it based on a timely topic that learners would like to have a quick refresher on while on-the-go, or would this lesson be better presented if delivered in a device with a larger form factor or in a physical class?

\section{2. $O$ is for "Off-the-shelf"}

The next general design consideration is for instructors to consider off-the-shelf solutions versus creating materials from scratch. For example, it would be more efficient to curate a publicly available animation that could present the materials in a visually appealing manner, than for the instructor to create a similar animation but at the expense of more time spent.

\section{3. $\mathrm{H}$ is for "브oney at the fingertips"}

The last general design consideration is for instructors to remind themselves to design their mobile lessons to be interactive so as to keep the attention of learners. Instructors would want to design their mobile lesson so that the lesson seems to be like "honey" which learners would like to "taste" from.

\subsection{I is for "An Icebox is NOT a refrigerator"}

This is the first design strategy drawn from the quality dimensions i.e. dimensions 3 and 4 (readability and navigability). Mobile learning has such distinct features that normal elearning lessons cannot be counted as a model mobile lesson. Instructors can use this visual metaphor for an icebox versus a refrigerator to remind themselves to not confuse desktop elearning with mobile learning. 


\subsection{C is for “Chunk it!"}

To facilitate retention for learners of a mobile lesson, chunking large amount of information into small parts helps people to remember things better. For this reason, mobile lesson designers are reminded to chunk both their learning outcomes and contents into small "nuggets” of information to aid learning, vis-à-vis quality dimensions 1 and 2 respectively.

\subsection{A is for "Assets on wheels"}

Mobile lessons should be self-contained i.e. each lesson should have learning outcomes that are taught via mobile-enabled learning activities and finally assessed at the end of the lesson. This would allow each mobile lesson to be accessed in a non-linear manner, in line with the concept of "just-in-time" learning.

\section{7. $N$ is for "Creating a Learning Nexus"}

With regards to quality dimensions 6 and 7, which suggest respectively that the learner's progress be tracked and social interaction for learning be introduced, we recommend that the mobile lesson be integrated into a Learning Management System (LMS) to tap on the LMS's in-built login system, discussion forum etc.

\section{8. $S$ is for "Self-Assessment"}

Lastly, quality dimensions 8 (assessment) and 9 (timely feedback) are mapped unto the strategy of self-assessment. Mobile lessons should have both in-content mid-lesson quizzes for knowledge checks, as well as summative assessments to gauge the overall learning outcomes of the learners.

\section{Methods}

Participants in the present study consisted of 120 identified learners from 2 faculties namely, School of Information Technology and School of Health Sciences. The participating instructors designed their mobile learning contents in accordance to the mobile learning teaching model that was highlighted in this paper. The learning contents were developed using various tools that support mobile learning. This study aims to find out how quality dimensions and strategies can enhance the quality of learners' learning. Each learner was surveyed to answer the following questions:

1. The learning outcomes are clear and concise.

2. The content is bite-sized for learning on-the-go.

3. The content is easily navigable.

4. The content is readable on a smart device. 
5. The content helped me in fulfilling the assessment required for this topic.

6. There are timely and constructive feedback to support learning.

7. The mobile learning contents have been helpful to me in my learning.

8. The mobile learning contents are self-paced, self-directed and relevant.

9. Overall, I find that mobile learning is good way of learning for me.

Besides the survey results from the learners, the authors examined the module learning outcomes through classroom observations coupled with discussion with the instructors to gauge the level of instructors' satisfaction as well as the level of attainment learners achieved in the required competencies.

\section{Results and Discussion}

In this section, we will discuss the results that was derived from the methods that were explained above. The results from the survey shows that the learners felt that mobile learning has helped them in their learning. Results has also shown that $90 \%$ of the learners felt that the mobile learning is good way of learning for them.

The following are the key results of the responses collected from the survey.

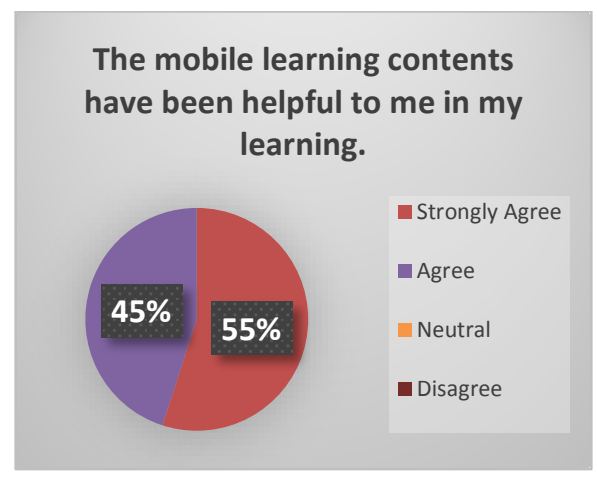

Figure 3: The mobile learning contents have been helpful to me in my learning.

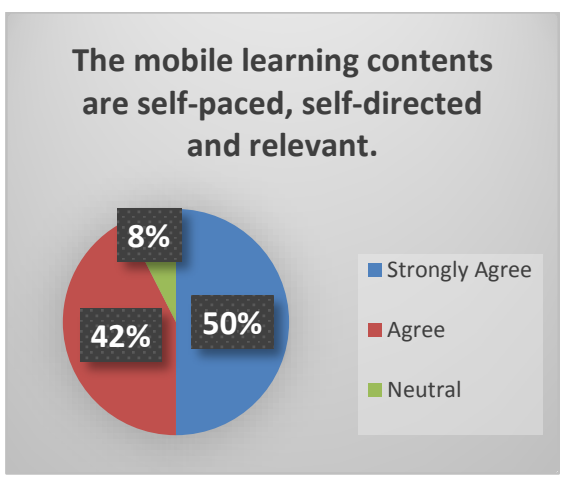

Figure 4: The mobile learning contents are selfpaced, self-directed and relevant. 
Table 1. Principle Results of Mobile Learning

\begin{tabular}{cc}
\hline $\begin{array}{c}\text { Overall, I find that mobile learning is good } \\
\text { way of learning for me }\end{array}$ & Percentage (\%) \\
\hline Strongly Agree & 42 \\
Agree & 48 \\
Neutral & 10 \\
Disagree & 0 \\
Strongly Disagree & 0 \\
\hline
\end{tabular}

Both qualitative data and sentiments collected from survey and classroom observations have been encouraging. Sediments from the feedback gathered have indicated that the positive acceptance of the proposed teaching and learning model by both the learners and instructors. Analysis of the collected data give suggestion that mobile learning was effective than the use of traditional teaching pedagogy to achieve the learning outcomes of the topics that the contents are developed in mobile learning packages. Results have also suggested that by using these quality dimensions and design strategies dedicated for developing mobile learning content, there is an increase of interest in learners' learning and has enriched the learners' experience. The instructors have also feedback that the teaching model and mnemonic MOHICANS have provided them practical design strategies that helped them to design learning contents suitable for mobile learning. From the score that the learners have achieved in the summative assessment, it can be determined that the learners have achieved the learning outcomes desired of the mobile learning contents. Most of the learners are able to score above $80 \%$ after going through the mobile learning contents.

\section{Conclusions and Recommendations}

Research has shown that the learner's experience on a mobile device is very different from any other traditional eLearning platforms (e.g. desktop). We have proposed a specialized design model for mobile learning. This study has proposed a 2-middle-layer-approach built upon Koole’s FRAME model with quality dimensions (1st layer) and strategies (2nd layer) that lead to a sound mobile lesson design. The results collected from the survey demonstrated the effectiveness of the recommended model.

The present study is administered to analyze the advantages of using design strategies that was recommended in the mobile learning model. The outcome is measured from the learner and instructor perspective. Quantitative feedback are collected through survey conducted with the 120 learners. 6 instructors are requested to develop mobile learning content based 
on the quality dimensions recommended for the modules that they teach respectively. 120 learners from 2 faculty contributed to the survey results. Qualitative feedback are also collected from the instructors through classroom observations and interviews. Overall, the survey has shown more than $85 \%$ of the respondents responded with 'Strong Agree' or 'Agree' for each question. Therefore, the summarized findings of this study reveal that our proposed approach maybe effective and practical for learners learning on-the-go, anytime and anywhere.

\section{References}

Campbell, M. A. (2005) The impact of the mobile phone on young people's social life. In Social Change in the 21st Century Conference, 28 October 2005, QUT Carseldine, Brisbane.

How to engage millennials: 5 teaching strategies for millennials that will work! (2017, March 30). Retrieved from https://www.efrontlearning.com/blog/2016/03/5-strategies-toengage-the-millennials.html

Koole, M. L. (2009). A model for framing mobile learning. Mobile learning: Transforming the delivery of education and training, 1(2), 25-47.

Ling, R. (2000, August). The impact of the mobile telephone on four established social institutions. In ISSEI2000 Conference of the International Society for the Study of European Ideas, Bergen Norway (pp. 14-18).

Oberer, B., \& Erkollar, A. (2013). Mobile Learning in Higher Education: A Marketing Course Design Project in Austria. Procedia - Social and Behavioral Sciences,93, 21252129. doi:10.1016/j.sbspro.2013.10.177

Parsons, D., \& Ryu, H. (2006, April). A framework for assessing the quality of mobile learning. In Proceedings of the International Conference for Process Improvement, Research and Education (pp. 17-27).

Sharples, M., Amedillo, S. I., Milrad, M. \& Vavoula, G. (2009). Mobile learning: small devices, big issues. In: Balacheff, N., Ludvigsen, S., Jong, T. de \& Barnes, S. (Eds.) Technology Enhanced Learning: Principles and Products. Heidelberg, Germany: Springer, pp. 233-249.

Taleb, Z., \& Sohrabi, A. (2012). Learning on the Move: The use of Mobile Technology to Support Learning for University Students. Procedia - Social and Behavioral Sciences,69, 1102-1109. doi:10.1016/j.sbspro.2012.12.038

Wang, M., Shen, R., Novak, D., \& Pan, X. (2009). The impact of mobile learning on students learning behaviours and performance: Report from a large blended classroom. British Journal of Educational Technology,40(4), 673-695. doi:10.1111/j.14678535.2008.00846.x 